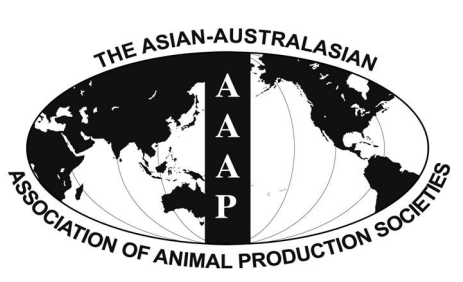

Open Access

Asian Australas. J. Anim. Sci.

Vol. 28, No. 12 : 1751-1759 December 2015

http://dx.doi.org/10.5713/ajas.14.0498

www.ajas.info

pISSN 1011-2367 elSSN 1976-5517

\title{
The Effect of Inclusion Level of Soybean Oil and Palm Oil on Their Digestible and Metabolizable Energy Content Determined with the Difference and Regression Method When Fed to Growing Pigs
}

\author{
Yongbo Su, Yue She, Qiang Huang, Chuanxin Shi, Zhongchao Li, \\ Chengfei Huang, Xiangshu Piao, and Defa $\mathrm{Li}^{*}$ \\ State Key Laboratory of Animal Nutrition, College of Animal Science and Technology, \\ China Agricultural University, Beijing 100093, China
}

\begin{abstract}
This experiment was conducted to determine the effects of inclusion level of soybean oil (SO) and palm oil (PO) on their digestible and metabolism energy (DE and ME) contents when fed to growing pigs by difference and regression method. Sixty-six crossbred growing barrows (Duroc $\times$ Landrace $\times$ Yorkshire and weighing $38.1 \pm 2.4 \mathrm{~kg}$ ) were randomly allotted to a $2 \times 5$ factorial arrangement involving 2 lipid sources (SO and PO), and 5 levels of lipid (2\%, 4\%,6\%,8\%, and 10\%) as well as a basal diet composed of corn and soybean meal. The barrows were housed in individual metabolism crates to facilitate separate collection of feces and urine, and were fed the assigned test diets at $4 \%$ of initial body weight per day. A 5-d total collection of feces and urine followed a 7-d diet adaptation period. The results showed that the DE and ME contents of SO and PO determined by the difference method were not affected by inclusion level. The DE and ME determined by the regression method for SO were greater compared with the corresponding respective values for PO (DE: 37.07, ME: $36.79 \mathrm{MJ} / \mathrm{kg}$ for SO; DE: 34.11, ME: $33.84 \mathrm{MJ} / \mathrm{kg}$ for PO, respectively). These values were close to the DE and ME values determined by the difference method at the $10 \%$ inclusion level (DE: $37.31, \mathrm{ME}: 36.83 \mathrm{MJ} / \mathrm{kg}$ for SO; DE: 34.62 , ME: $33.47 \mathrm{MJ} / \mathrm{kg}$ for PO, respectively). A similar response for the apparent total tract digestibility of acid-hydrolyzed ether extract (AEE) in lipids was observed. The true total tract digestibility of AEE in SO was significantly $(\mathrm{p}<0.05)$ greater than that for PO ( $97.5 \%$ and $91.1 \%$, respectively). In conclusion, the DE and ME contents of lipid was not affected by its inclusion level. The difference method can substitute the regression method to determine the DE and ME contents in lipids when the inclusion level is $10 \%$. (Key Words: Digestibility, Energy Content, Inclusion Level, Palm Oil, Pigs, Soybean Oil)
\end{abstract}

\section{INTRODUCTION}

Lipids are an important dietary energy source with a high energy content and high digestibility for swine ( $\mathrm{Li}$ et al., 1990; Jone et al., 1992; Jørgensen and Fernandez, 2000). An accurate determination of the energy content of a lipid is important for utilizing it appropriately in the feed industry. The determined energy values for the same source of lipid in different studies are not consistent (Wiseman et al., 1990; Powles et al., 1993; Jørgensen et al., 2000). In addition to breed of animal, basal diet, and determination method, the

\footnotetext{
* Corresponding Author: Defa Li. Tel: +86-10-62733691, Fax: +86-10-62733688, E-mail: defali@mafic.ac.cn

Submitted Jul. 5, 2014; Revised Sept. 30, 2014; Accepted Dec. 1, 2014
}

inclusion level of the lipid is an important factor that affects the accuracy of the determination of the energy value of a lipid (Allee et al., 1971; Kil et al., 2011).

The extensively used prediction equation for the energy value of lipids is based on free fatty acids content and degree of saturation. However, increasing the inclusion level of lipid can affect the values for the digestibility of acid-hydrolyzed ether extract (AEE), dry matter (DM), crude protein $(\mathrm{CP})$, and some amino acids in growing pigs (Jørgensen et al., 2000; Albin et al., 2001; Bruce et al, 2006; Rojas-Cano et al., 2014). Therefore, there is a hypothesis that interactions exist between the basal diet and the supplemented lipid which result in changes in the determined energy value of the lipid. To our knowledge, 
there is limited information about systematic evaluation of the energy value of different dietary lipids for pigs.

The composition of the fatty acids in lipids may affect their digestibility, such as saturated or unsaturated lipid (Wiseman et al., 1990; Powles et al., 1993; Jørgensen and Fernandez, 2000; Kil et al., 2011). In addition, the effect of inclusion level on the digestibility and energy value of a saturated or unsaturated lipid might be different. Therefore, the objective of this study was to determine the effect of inclusion level of soybean oil (SO) and palm oil (PO) on their digestible energy (DE) and metabolism energy (ME) contents determined by difference and regression method.

\section{MATERIALS AND METHODS}

\section{General procedures}

The experimental protocol used in this study was approved by the Institutional Animal Care and Use Committee at China Agricultural University (Beijing, China). This study was conducted in the Metabolism Laboratory of the National Feed Engineering Technology Research Center (HeBei Province, China).

The barrows were housed individually in stainless steel metabolism cages $(1.4 \times 0.7 \times 0.6 \mathrm{~m})$ equipped with a feeder and a nipple drinker. The crates were located in six environmentally controlled rooms with the temperature maintained at $22^{\circ} \mathrm{C}$ to $24^{\circ} \mathrm{C}$. To minimize the opportunity for environmental effects to confound the results, one pig per treatment was allotted to each room. The pigs were allowed a 10 day period to adapt to the metabolism crates and the environmental conditions of the room. During this period, the pigs were fed a commercial diet and feed intake was gradually increased until the daily feed allowance reached $4 \%$ of the pig's body weight (Adeola, 2001). Pigs were weighed at the beginning of the adaptation period.

Sixty-six crossbred growing barrows (Duroc $\times$ Landrace $\times$ Yorkshire and weighing $38.1 \pm 2.4 \mathrm{~kg}$ ) were randomly allotted to a $2 \times 5$ factorial arrangement involving 2 lipid sources ( $\mathrm{SO}$ and $\mathrm{PO}$ ), and 5 levels of lipid (2\%, 4\%, 6\%, $8 \%$, and $10 \%$ ) as well as a basal diet composed of corn and soybean meal (Table 1). Basal diet was substituted for lipid at graded levels $(2 \%, 4 \%, 6 \%, 8 \%$, and $10 \%)$ according to the difference procedure (Kong and Adeola, 2014). The SO and $\mathrm{PO}$ were food grade $(\mathrm{FFA}<0.2 \%)$. The fatty acid profile of the lipids was presented in Table 2 .

All experimental diets were supplemented with the same proportion of dicalcium phosphate, limestone, salt, and vitamin-mineral premix to meet or exceed the estimated nutrient requirements for growing pigs as recommended by NRC (2012).

Feed was provided in mash form twice daily at 08:00 and 17:00 h. Water was available continuously through a low-pressure nipple drinker. A 5-d period for total collection of feces and urine followed a 7-d period for diet adaptation. Feed remnants and feed spillage were collected, dried and weighed accurately to calculate feed intake.

Feces were collected immediately as they appeared in the metabolism crates and placed in plastic bags to be stored at $-20^{\circ} \mathrm{C}$. Urine was collected in a bucket placed under the metabolism crate. The bucket contained $10 \mathrm{~mL}$ of $6 \mathrm{~N} \mathrm{HCl}$

Table 1. Ingredient composition and chemical analysis of the experimental diets ( $\%$ as-fed)

\begin{tabular}{|c|c|c|c|c|c|c|c|c|c|c|c|}
\hline \multirow{2}{*}{ Level of added oil (\%) } & \multicolumn{6}{|c|}{ Soybean oil } & \multicolumn{5}{|c|}{ Palm oil } \\
\hline & 0 & 2 & 4 & 6 & 8 & 10 & 2 & 4 & 6 & 8 & 10 \\
\hline \multicolumn{12}{|l|}{ Ingredient (\%) } \\
\hline Corn & 75.40 & 73.85 & 72.30 & 70.76 & 69.21 & 67.66 & 73.85 & 72.30 & 70.76 & 69.21 & 67.66 \\
\hline Soybean meal & 22.00 & 21.55 & 21.10 & 20.64 & 20.19 & 19.74 & 21.55 & 21.10 & 20.64 & 20.19 & 19.74 \\
\hline Soybean oil & - & 2.00 & 4.00 & 6.00 & 8.00 & 10.00 & - & - & - & - & - \\
\hline Palm oil & - & - & - & - & - & & 2.00 & 4.00 & 6.00 & 8.00 & 10.00 \\
\hline Dicalcium phosphate & 0.90 & 0.90 & 0.90 & 0.90 & 0.90 & 0.90 & 0.90 & 0.90 & 0.90 & 0.90 & 0.90 \\
\hline Limestone & 0.90 & 0.90 & 0.90 & 0.90 & 0.90 & 0.90 & 0.90 & 0.90 & 0.90 & 0.90 & 0.90 \\
\hline Salt & 0.30 & 0.30 & 0.30 & 0.30 & 0.30 & 0.30 & 0.30 & 0.30 & 0.30 & 0.30 & 0.30 \\
\hline Vitamin-mineral premix ${ }^{1}$ & 0.50 & 0.50 & 0.50 & 0.50 & 0.50 & 0.50 & 0.50 & 0.50 & 0.50 & 0.50 & 0.50 \\
\hline \multicolumn{12}{|l|}{ Analyzed composition (\%) } \\
\hline Dry matter & 87.83 & 88.12 & 88.34 & 88.54 & 88.84 & 89.15 & 88.17 & 88.34 & 88.55 & 88.81 & 89.05 \\
\hline Acid-hydrolyzed ether extract & 2.91 & 4.98 & 7.09 & 9.01 & 10.55 & 12.57 & 5.32 & 7.21 & 9.13 & 10.84 & 12.78 \\
\hline Crude protein & 16.06 & 15.86 & 15.35 & 15.11 & 14.96 & 14.62 & 15.83 & 15.55 & 15.11 & 15.06 & 14.41 \\
\hline Neutral detergent fiber & 8.35 & 8.12 & 7.72 & 7.79 & 7.07 & 7.32 & 8.16 & 8.18 & 7.55 & 7.64 & 7.06 \\
\hline Acid detergent fiber & 2.43 & 2.38 & 2.31 & 2.29 & 2.14 & 2.13 & 2.60 & 2.48 & 2.31 & 2.20 & 2.31 \\
\hline Ash & 4.36 & 4.25 & 4.32 & 4.12 & 4.26 & 4.16 & 4.50 & 4.26 & 4.21 & 4.27 & 4.11 \\
\hline
\end{tabular}

${ }^{1}$ Premix provided the following per kg of complete diet for growing pigs: vitamin $\mathrm{A}, 5,512 \mathrm{IU}$; vitamin $\mathrm{D}_{3}$, 2,200 IU; vitamin $\mathrm{E}$, 30 IU; vitamin $\mathrm{K}_{3}$, 2.2 $\mathrm{mg}$; vitamin $\mathrm{B}_{12}, 27.6 \mu \mathrm{g}$; riboflavin, $4 \mathrm{mg}$; pantothenic acid, $14 \mathrm{mg}$; niacin, $30 \mathrm{mg}$; choline chloride, $400 \mathrm{mg}$; folacin, $0.7 \mathrm{mg}$; thiamine $1.5 \mathrm{mg}$; pyridoxine $3 \mathrm{mg}$; biotin, $44 \mu \mathrm{g}$; $\mathrm{Mn}, 40 \mathrm{mg}(\mathrm{MnO})$; Fe, $75 \mathrm{mg}\left(\mathrm{FeSO}_{4} \cdot \mathrm{H}_{2} \mathrm{O}\right) ; \mathrm{Zn}, 75 \mathrm{mg}(\mathrm{ZnO}) ; \mathrm{Cu}, 100 \mathrm{mg}\left(\mathrm{CuSO} \cdot 5 \mathrm{H}_{2} \mathrm{O}\right) ; \mathrm{I}, 0.3 \mathrm{mg}(\mathrm{KI})$; $\mathrm{Se}, 0.3 \mathrm{mg}$ $\left(\mathrm{Na}_{2} \mathrm{SeO}_{3}\right)$. 
Table 2. The fatty acid profile of lipids

\begin{tabular}{lcc}
\hline Item & Soybean oil & Palm oil \\
\hline Fatty acid (\% of lipid) & & \\
C8:0 & 0.13 & 0.13 \\
C12:0 & 0.01 & 0.13 \\
C14:0 & 0.10 & 0.88 \\
C16:0 & 11.49 & 46.16 \\
C16:1 & 0.09 & 0.13 \\
C18:0 & 4.33 & 5.07 \\
C18:1 & 23.67 & 37.18 \\
C18:2 & 52.80 & 9.08 \\
C18:3 & 5.77 & 0.36 \\
C20:0 & 0.41 & 0.41 \\
C20:1 & 0.21 & 0.10 \\
C22:0 & 0.45 & 0.08 \\
C24:0 & 0.17 & 0.08 \\
Others & 0.35 & 0.23 \\
SFA & 17.34 & 53.12 \\
MUFA & 24.03 & 37.43 \\
PUFA & 58.62 & 9.44 \\
\hline
\end{tabular}

SFA, saturated fatty acid; MUFA, monounsaturated fatty acid; PUFA, polyunsaturated fatty acid.

for every $1,000 \mathrm{~mL}$ of urine. Each day, the total urine volume was measured and a $10 \%$ aliquot was filtered through gauze and the urine samples were transferred into a screw-capped tube and immediately stored at $-20^{\circ} \mathrm{C}$ until needed for analysis. At the end of the collection period, feces were thawed, pooled, homogenized, sub-sampled, dried for $72 \mathrm{~h}$ at $65^{\circ} \mathrm{C}$ in a forced-air drying oven and ground through a 1-mm screen before chemical analysis.

\section{Chemical analysis}

All chemical analyses were conducted in duplicate and repeated if the results differed by more than $5 \%$. Feed and fecal samples were analyzed for DM (AOAC method 934.01), AEE (AOAC method 954.02), CP (AOAC method 990.03), crude fiber (AOAC method 978.10), and ash (AOAC method 942.05). The content of neutral detergent fiber (NDF) and acid detergent fiber (ADF) were determined using filter bags and fiber analyzer equipment (Fiber Analyzer, Ankom Technology, Macedon, NY, USA) following a modification of the procedure of Van Soest et al. (1991). The content of gross energy (GE) was determined using an Automatic Adiabatic Oxygen Bomb Calorimeter (Parr 6300 Calorimeter, Moline, IL, USA). The fatty acid profiles of the lipid sources were determined by gas chromatography $(6890$ series, Agilent Technologies, Wilmington, DE, USA) following the procedures of Sukhija and Palmquist (1988).

\section{Calculations and statistical analyses}

The apparent total tract digestibility (ATTD) of AEE,
DM, NDF, ADF, and CP were calculated for each diet. The true total tract digestibility (TTTD) of lipid was calculated using the regression method. The apparent digested fat $(\mathrm{g} / \mathrm{kg}$ of dry matter intake [DMI]) of the entire intestinal tract was regressed against dietary fat intake $(\mathrm{g} / \mathrm{kg} \mathrm{DM})$ for each pig. The slope of the regression line represented the true digestibility of lipid, whereas the Y-intercept of this regression equation was considered the endogenous loss of AEE (g/kg of DMI) (Jørgensen et al., 1993).

The DE and ME values of $\mathrm{SO}$ were calculated using the following equations:

$$
\begin{aligned}
& \mathrm{DE}_{\text {lipid }} \\
& =\frac{\text { wt. feed intake } \times \mathrm{DE}_{\text {feed }}-\text { wt. EYI intake } \times \mathrm{DE}_{\mathrm{EYI}}}{\text { wt. lipid intake }} \\
& \mathrm{ME}_{\text {lipid }} \\
& =\frac{\text { wt. feed intake } \times \mathrm{ME}_{\text {feed }}-\text { wt. EYI intake } \times \mathrm{ME}_{\mathrm{EYI}}}{\mathrm{wt} \text {. lipid intake }}
\end{aligned}
$$

In these equations, wt. = weight and EYI $=$ energyyielding ingredient of basal diet. Because the proportion of the EYI in basal diets was 0.974 , the energy concentration of EYI was calculated by dividing the DE or ME of the basal diet by 0.974 .

The ATTD of lipid contained in each experimental diet was calculated using the following equation:

$$
\begin{aligned}
& D_{\text {lipid }}
\end{aligned}
$$

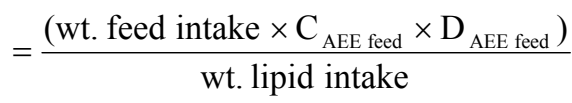

$$
\begin{aligned}
& -\frac{\left(\text { wt. EYI intake } \times \mathrm{C}_{\mathrm{AEE} \mathrm{EYI}} \times \mathrm{D}_{\mathrm{AEE} \mathrm{EYI}}\right)}{\text { wt. lipid intake }}
\end{aligned}
$$

In this equation, $\mathrm{C}_{\mathrm{AEE}}=$ the concentration of $\mathrm{AEE}$ and $\mathrm{D}_{\mathrm{AEE}}=$ the digestibility of AEE.

The UNIVARIATE procedure of SAS was used to check for normal distribution of the model residuals and equal variances. The residual vs the predicted plot procedure was used to identify outliers. The model included the effect of basal diet, inclusion level of $\mathrm{SO}$ and their interaction for all measurements. Data were analyzed using the MIXED procedure of SAS (SAS Inst. Inc., Cary NC, USA). The individual animal and dietary treatment were the experimental units for analyzing the data from the digestibility trial. The model included diet as a fixed effect and animal as a random effect. Orthogonal polynomial contrasts were used to detect linear and quadratic responses to inclusion level of lipid. The REG procedure of SAS was used to estimate the Y-intercept of the regression line for determining endogenous loss of AEE, and the slope was 
Table 3. The digestible (DE) and metabolizable energy (ME) contents of the experimental diets (as-fed basis) ${ }^{1}$

\begin{tabular}{|c|c|c|c|c|c|c|c|c|c|c|}
\hline \multirow{2}{*}{ Item } & \multicolumn{6}{|c|}{ Inclusion level (\%) } & \multirow{2}{*}{ SEM } & \multicolumn{3}{|c|}{ p-value } \\
\hline & 0 & 2 & 4 & 6 & 8 & 10 & & Level & Source & Interaction \\
\hline \multicolumn{11}{|l|}{$\overline{\mathrm{DE}}(\mathrm{MJ} / \mathrm{kg})$} \\
\hline Soybean oil ${ }^{2}$ & 14.15 & 14.47 & 14.94 & 15.39 & 15.92 & 16.42 & 0.142 & $<0.001$ & 0.022 & 0.324 \\
\hline Palm oil $^{2}$ & 14.15 & 14.46 & 14.91 & 15.33 & 15.75 & 16.15 & 0.127 & & & \\
\hline \multicolumn{11}{|l|}{$\mathrm{ME}(\mathrm{MJ} / \mathrm{kg})$} \\
\hline Soybean oil ${ }^{2}$ & 13.87 & 14.19 & 14.64 & 15.08 & 15.56 & 16.13 & 0.148 & $<0.001$ & 0.075 & 0.370 \\
\hline Palm oil ${ }^{2}$ & 13.87 & 14.18 & 14.62 & 15.02 & 15.43 & 15.80 & 0.116 & & & \\
\hline \multicolumn{11}{|l|}{ ME/DE (\%) } \\
\hline Soybean oil & 98.08 & 98.06 & 98.09 & 97.98 & 97.93 & 98.23 & 0.120 & 0.608 & 0.995 & 0.924 \\
\hline Palm oil & 98.08 & 98.05 & 98.02 & 97.98 & 97.94 & 97.79 & 0.109 & & & \\
\hline
\end{tabular}

SEM, standard error of the mean

${ }^{1} \mathrm{n}=6$ per mean. ${ }^{2}$ Linear effect of inclusion level at $\mathrm{p}<0.001$.

used to determine the TTTD for lipid. Intercepts and slopes were compared between the two basal diets based on confidence intervals coefficients for regression lines (Dilger and Adeola, 2006). The level of significance adopted was $5 \%(\mathrm{p}<0.05)$ to assess differences among means.

\section{RESULTS}

All pigs remained healthy and readily consumed their diets without any problems. Both feces and urine were successfully collected from all pigs. The DE and ME contents of the experimental diets linearly increased $(p<0.001)$ as inclusion level increased regardless of lipid source (Table 3$)$. The lipid source significantly $(p=0.022)$ affected the DE content of the experimental diets but did not affect the ME content of the experimental diets ( $p=$ 0.075). The average ratio of ME to DE for diets containing lipid was $98 \%$.

At least two outliers were presented in the $2 \%$ inclusion level treatment for DE and ME of lipids. The coefficient of variance of $\mathrm{DE}$ and $\mathrm{ME}$ contents within replications decreased inversely as the inclusion level of lipid increased $\left(\mathrm{p}<0.01, \mathrm{R}^{2}>0.9\right.$, Figure 1). The coefficients of variance for the DE and ME contents of lipids at the $2 \%$ inclusion level were greater than $23 \%$ after excluding the outliers. This was due to the calculation method of difference method. The stand error of energy value for 2\% inclusion level (not shown in Table 4) was also much greater than other higher level treatments, which was similar to the result of Villamied (1996). Therefore, in the process of data analysis, it was inappropriate to analyze the effect of inclusion level on $\mathrm{DE}$ or ME of lipids determined by difference method including $2 \%$ level treatment.

The determined DE and ME contents of SO and PO by the difference method were not affected by inclusion level (Table 4). The lipid source significantly affected the DE content of lipids $(p<0.05)$. However, the ME content was not affected by lipid source $(\mathrm{p}=0.145)$. There was no effect of inclusion level and lipid source on the ratio of ME/DE for lipids. The ME was $97.73 \%$ and $97.07 \%$ of DE for SO and $\mathrm{PO}$ respectively, which are close to the recommended value $98 \%$ in NRC (2012).

The DE and ME contents of SO and PO were also determined by the regression method. The values of $\mathrm{DE}$ and

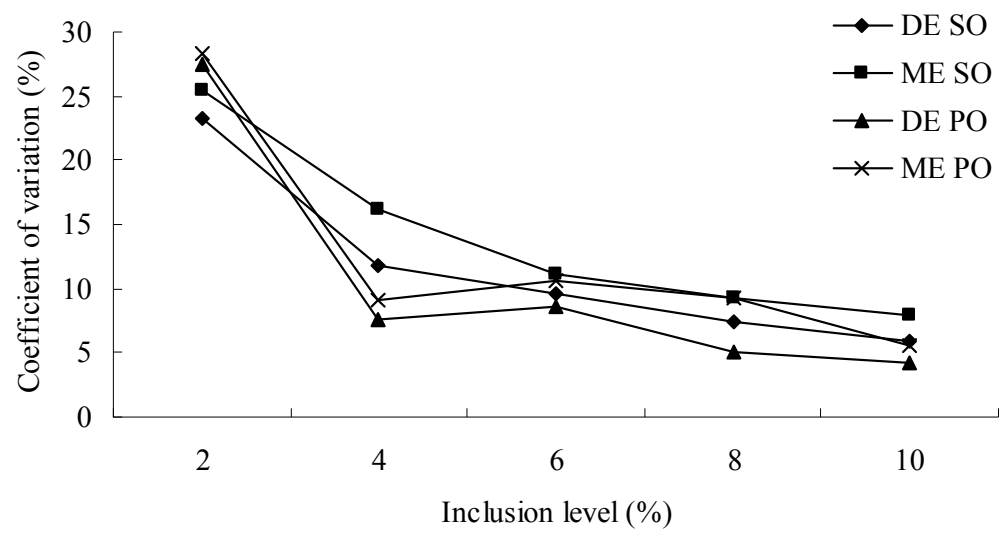

Figure 1. Effect of the inclusion level on the coefficient of variation of the determined DE and ME contents of lipids. $\mathrm{n}=5$. The coefficient of variance of $\mathrm{DE}$ and $\mathrm{ME}$ contents within replications decreased inversely as the inclusion level of lipids increased ( $\mathrm{p}<0.01$, $\mathrm{R}^{2}>0.9$ ). DE, digestible energy, ME, metabolism energy, SO, soybean oil; PO, palm oil. 
Table 4. The digestible (DE) and metabolizable energy (ME) contents of soybean oil and palm oil determined by the difference method in growing pigs ${ }^{1,2}$

\begin{tabular}{|c|c|c|c|c|c|c|c|c|c|}
\hline \multirow{2}{*}{ Item } & \multicolumn{5}{|c|}{ Inclusion level (\%) } & \multirow{2}{*}{ SEM } & \multicolumn{3}{|c|}{$\mathrm{p}$-value } \\
\hline & 4 & 6 & 8 & 10 & Mean value & & Level & Source & Interaction \\
\hline \multicolumn{10}{|l|}{$\overline{\mathrm{DE}}(\mathrm{MJ} / \mathrm{kg})$} \\
\hline Soybean oil & 34.51 & 35.25 & 36.74 & 37.31 & 35.95 & 0.650 & 0.345 & 0.047 & 0.816 \\
\hline Palm oil & 33.63 & 34.31 & 34.59 & 34.62 & 34.27 & 0.447 & & & \\
\hline \multicolumn{10}{|l|}{ ME (MJ/kg) } \\
\hline Soybean oil & 33.35 & 34.29 & 35.26 & 36.83 & 34.99 & 0.857 & 0.573 & 0.145 & 0.787 \\
\hline Palm oil & 32.81 & 33.38 & 33.65 & 33.47 & 33.34 & 0.582 & & & \\
\hline \multicolumn{10}{|l|}{ ME/DE (\%) } \\
\hline Soybean oil & 97.66 & 97.24 & 97.32 & 98.63 & 97.73 & 1.031 & 0.994 & 0.649 & 0.953 \\
\hline Palm oil & 97.33 & 97.18 & 97.13 & 96.70 & 97.07 & 0.740 & & & \\
\hline
\end{tabular}

SEM, standard error of the mean.

${ }^{1} \mathrm{n}=6$ per mean.

${ }^{2}$ The $2 \%$ inclusion level was not used to analyze the effect of inclusion level on the DE and ME contents of lipids, because at least two outliers were presented in the $2 \%$ inclusion level treatment for DE and ME of lipids, and the coefficients of variation were still greater than $23 \%$ after excluding the outliers.

ME for SO were greater compared with the corresponding values for PO (DE: 37.07, ME: $36.79 \mathrm{MJ} / \mathrm{kg}$ for SO; DE: 34.11, ME: $33.84 \mathrm{MJ} / \mathrm{kg}$ for PO, respectively, Table 5). The values of $\mathrm{DE}$ and $\mathrm{ME}$ for $\mathrm{SO}$ and $\mathrm{PO}$ derived from the regression method were not significantly different from the values derived from the difference method determined by a $t$-test, so that the result was not shown in a Table 5.

The ATTD of AEE in SO and PO for all inclusion levels were calculated in the present experiment. Likewise, it was similar to the DE and ME of lipids, the $2 \%$ level treatment was also not used to analyze the effect of inclusion level on the ATTD of AEE in lipid determined by difference method.
As the inclusion level increased, the ATTD of AEE in SO increased, while the ATTD of AEE in PO decreased, but the differences were not statistically significant (Table 6). The inclusion level of the dietary lipids did not affect the ATTD of AEE in lipids, but there was a significant difference ( $p=$ 0.002) between the ATTD of AEE in SO and PO.

The regression of total tract digested AEE against the intake of AEE was significant for SO and PO $\left(p<0.001, \mathrm{R}^{2}\right.$ $>0.99$, Table 7). The TTTD of AEE in SO, calculated from the slope of the regression equation, was significantly greater $(\mathrm{p}<0.001)$ than that for PO $(97.5 \%$ and $91.1 \%$, respectively). The $y$-intercepts that represented the

Table 5. The digestible (DE) and metabolizable energy (ME) of soybean oil and palm oil determined by the regression method

\begin{tabular}{|c|c|c|c|c|c|c|c|}
\hline \multirow{2}{*}{ Item } & \multirow{2}{*}{ Regression equation $^{2}$} & \multirow{2}{*}{$\mathrm{R}^{2}$} & \multicolumn{2}{|c|}{ Intercept } & \multicolumn{2}{|c|}{ Slope } & \multirow{2}{*}{$\begin{array}{c}\text { When } \mathrm{x}=1,000, \\
\mathrm{DE} / \mathrm{ME}\end{array}$} \\
\hline & & & SE & p-value & SE & $\mathrm{p}$-value & \\
\hline \multicolumn{8}{|l|}{$\mathrm{DE}(\mathrm{MJ} / \mathrm{kg})$} \\
\hline Soybean oil & $y=0.023 x+14.07$ & 0.946 & 0.060 & $<0.001$ & 0.001 & $<0.001$ & 37.07 \\
\hline Palm oil & $y=0.020 x+14.11$ & 0.961 & 0.045 & $<0.001$ & 0.001 & $<0.001$ & 34.11 \\
\hline \multicolumn{8}{|l|}{ ME (MJ/kg) } \\
\hline Soybean oil & $y=0.023 x+13.79$ & 0.920 & 0.076 & $<0.001$ & 0.001 & $<0.001$ & 36.79 \\
\hline Palm oil & $y=0.020 x+13.84$ & 0.932 & 0.060 & $<0.001$ & 0.001 & $<0.001$ & 33.84 \\
\hline
\end{tabular}

SE, standard error.

${ }^{1} \mathrm{n}=36$.

${ }^{2}$ These linear regression equations are all significant $(\mathrm{p}<0.001)$. In equation $\mathrm{y}=\mathrm{ax}+\mathrm{b}, \mathrm{y}=\mathrm{DE}$ or ME values of diet $(\mathrm{MJ} / \mathrm{kg}), \mathrm{x}=$ inclusion level of lipid $(\mathrm{g} / \mathrm{kg})$, and $\mathrm{b}=$ intercept.

Table 6. The apparent total tract digestibility (ATTD) of acid-hydrolyzed ether extract (AEE) in soybean oil and palm oil (\%) $)^{1,2}$

\begin{tabular}{|c|c|c|c|c|c|c|c|c|c|}
\hline \multirow{2}{*}{ Item } & \multicolumn{5}{|c|}{ Inclusion level (\%) } & \multirow{2}{*}{ SEM } & \multicolumn{3}{|c|}{ p-value } \\
\hline & 4 & 6 & 8 & 10 & Mean value & & Level & Source & Interaction \\
\hline Soybean oil & 93.12 & 93.87 & 94.47 & 95.83 & 94.32 & 0.649 & 0.997 & 0.002 & 0.260 \\
\hline Palm oil & 92.57 & 91.43 & 91.06 & 90.03 & 91.27 & 0.636 & & & \\
\hline
\end{tabular}

SEM, standard error of the mean.

${ }^{1} \mathrm{n}=6$ per mean.

${ }^{2}$ The $2 \%$ inclusion level was not used to analyze the effect of inclusion level on ATTD of lipids, because at least two outliers were presented in the $2 \%$ inclusion level treatment of lipids, and the stand error was much greater than the other levels. 
Table 7. The true total tract digestibility (TTTD) and the endogenous loss (EL) of acid-hydrolyzed ether extract (AEE) for soybean oil and palm oil determined through the regression of total apparently digested AEE ( $/ \mathrm{kg}$ of DMI) against the dietary AEE intake (g/kg of $\mathrm{DM})^{1}$

\begin{tabular}{|c|c|c|c|c|c|c|c|c|c|}
\hline \multirow{2}{*}{ Item } & \multirow{2}{*}{ Regression equation } & \multirow{2}{*}{$\mathrm{R}^{2}$} & \multicolumn{3}{|c|}{ EL of AEE ( $\mathrm{g} / \mathrm{kg}$ of DMI) } & \multicolumn{3}{|c|}{ TTTD (\%) } & \multirow{2}{*}{$\operatorname{ATTD}(\%)^{4}$} \\
\hline & & & Estimate & $\mathrm{SE}$ & p-value ${ }^{2}$ & Estimate & $\mathrm{SE}$ & p-value ${ }^{3}$ & \\
\hline Soybean oil & $y=0.975 x-14.02$ & 0.996 & 14.02 & 1.121 & $<0.001$ & $97.5^{\mathrm{a}}$ & 0.011 & $<0.001$ & $96.1^{\mathrm{a}}$ \\
\hline Palm oil & $y=0.911 x-10.80$ & 0.997 & 10.80 & 0.916 & $<0.001$ & $91.1^{\mathrm{b}}$ & 0.009 & $<0.001$ & $90.0^{\mathrm{b}}$ \\
\hline
\end{tabular}

DMI, dry matter intake; DM, dry matter, SE, standard error; ATTD, apparent total tract digestibility.

${ }^{1} \mathrm{n}=36$.

${ }^{2}$ The probability of significance for the intercept of the regression equation.

${ }^{3}$ The probability of significance for the slope of the regression equation.

${ }^{4}$ The apparent total tract digestibility, calculated as the $\mathrm{x}=1,000$, ATTD $=y / 1,000$.

${ }^{\mathrm{a}-\mathrm{b}}$ Within a column means followed by different letters are different $(\mathrm{p}<0.05)$.

endogenous losses for AEE of SO and PO were 14.02 and $10.80 \mathrm{~g} / \mathrm{kg}$ of DMI respectively ( $<<0.001)$. However, there was no difference between them. The ATTD of AEE in lipids were also calculated from these equations. The ATTD AEE in was greater for SO than PO $(96.1 \%$ and $90.0 \%$, respectively, $\mathrm{p}<0.05$ ).

A linear increase $(p<0.05$, Table 8$)$ in the ATTD of GE, $\mathrm{DM}, \mathrm{CP}$, and AEE and a quadratic increase $(\mathrm{p}<0.01)$ in the ATTD of AEE were observed in pigs fed diets containing $\mathrm{SO}$ as inclusion level increased. However, there was no effect of inclusion level on the ATTD of NDF and ADF in the diet containing SO. A quadratic increase $(p<0.05)$ in the ATTD of DM and a linear increase $(p<0.01)$ in the ATTD of AEE were observed in pigs fed diets containing PO as the inclusion level increased. However, no differences in the ATTD of GE, CP, NDF, and ADF were observed due to inclusion level. Lipid source affected the ATTD of GE and AEE for pigs fed diets containing SO or PO $(\mathrm{p}<0.01)$.

\section{DISCUSSION}

A linear increase in the ATTD of AEE for the experimental diets containing SO or PO with increasing inclusion level was observed and is in agreement with previous results from research with SO (Jørgensen et al., 1993; Kil et al., 2011, Adeola et al., 2013), corn oil (Kil et al., 2010), tallow (Adeola et al., 2013), poultry fat (Mendoza and Heugten, 2014) and rapeseed oil (Jørgensen

Table 8. The apparent total tract digestibility of dry matter (DM), crude protein (CP), acid-hydrolyzed ether extract (AEE), neutral detergent fiber (NDF), and acid detergent fiber (ADF) of each experimental diet $(\%)^{1}$

\begin{tabular}{|c|c|c|c|c|c|c|c|c|c|c|}
\hline \multirow{2}{*}{ Item } & \multicolumn{6}{|c|}{ Inclusion level (\%) } & \multirow{2}{*}{ SEM } & \multicolumn{3}{|c|}{ p-value } \\
\hline & 0 & 2 & 4 & 6 & 8 & 10 & & Level & Source & Interaction \\
\hline \multicolumn{11}{|l|}{$\overline{D M}$} \\
\hline Soybean oil ${ }^{2}$ & 88.75 & 88.22 & 88.72 & 89.12 & 89.66 & 90.34 & 0.212 & 0.001 & 0.082 & 0.829 \\
\hline Palm oil ${ }^{3}$ & 88.75 & 88.12 & 88.46 & 88.86 & 88.95 & 89.44 & 0.154 & & & \\
\hline \multicolumn{11}{|l|}{ GE } \\
\hline Soybean oil ${ }^{2}$ & 88.35 & 88.01 & 88.56 & 89.13 & 89.84 & 90.45 & 0.235 & 0.002 & 0.003 & 0.308 \\
\hline Palm oil & 88.35 & 87.92 & 88.13 & 88.51 & 88.46 & 88.81 & 0.154 & & & \\
\hline \multicolumn{11}{|l|}{$\mathrm{CP}$} \\
\hline Soybean oil & 87.80 & 87.44 & 87.62 & 87.96 & 88.64 & 89.17 & 0.244 & 0.169 & 0.280 & 0.873 \\
\hline Palm oil & 87.80 & 87.34 & 87.57 & 87.81 & 88.03 & 88.14 & 0.178 & & & \\
\hline \multicolumn{11}{|l|}{ AEE } \\
\hline Soybean oil ${ }^{2,3}$ & 59.45 & 72.54 & 78.54 & 82.44 & 86.02 & 88.38 & 1.710 & $<0.001$ & $<0.001$ & 0.067 \\
\hline Palm oil ${ }^{2}$ & 59.45 & 72.29 & 77.81 & 80.46 & 82.77 & 83.38 & 1.458 & & & \\
\hline \multicolumn{11}{|l|}{ NDF } \\
\hline Soybean oil & 52.25 & 46.53 & 52.34 & 52.41 & 53.08 & 52.71 & 0.906 & 0.141 & 0.113 & 0.983 \\
\hline Palm oil & 52.25 & 49.75 & 53.20 & 55.89 & 55.30 & 55.67 & 0.985 & & & \\
\hline \multicolumn{11}{|l|}{$\mathrm{ADF}$} \\
\hline Soybean oil & 49.27 & 44.51 & 52.91 & 49.83 & 50.88 & 50.59 & 1.178 & 0.607 & 0.062 & 0.592 \\
\hline Palm oil & 49.27 & 52.42 & 51.27 & 53.61 & 53.54 & 57.23 & 1.268 & & & \\
\hline
\end{tabular}

SEM, standard error of the mean; GE, gross energy; CP, crude protein.

${ }^{1} \mathrm{n}=6$ per mean.

${ }^{2}$ Linear effect of inclusion level at $\mathrm{p}<0.05$.

${ }^{3}$ Quadratic effect of inclusion level at $\mathrm{p}<0.05$. 
et al., 1996). Likewise, DE, ME and ATTD of DM and GE in diets increased with increasing inclusion level of lipids. This is due to the greater GE, DE, and ME contents and higher digestibility of AEE in lipid sources than in corn and soybean meal.

Observations of greater $\mathrm{DE}$ content and relatively greater $\mathrm{ME}$ content in diets containing $\mathrm{SO}$ than in diets containing PO, found in the current study, are not consistent with previous research which compared diets containing SO or tallow fed from d 21 to 35 postweaning (Adeola et al., 2013). The basis for this discrepancy is unclear but may be that the tallow had higher digestibility because of the position and distribution of saturated and unsaturated fatty acids on the triglyceride molecules within the tallow (Bracco, 1994; Ramírez et al., 2001).

In the current study, the DE and ME contents of lipids were determined at every inclusion level of lipids by the difference method. The DE and ME contents of the lipid sources were not affected by the dietary lipid level. However, the DE content of lipids was significantly affected by lipid source. The reason for the observation may be the greater digestibility of SO than PO. The ratio of unsaturated fatty acid to saturated fatty acid can affect the DE and ME contents of lipid (Wiseman et al., 1990; Powles et al., 1993; Jørgensen et al., 2000). However, lipid source did not affect the ME content of lipids in the current study, which was an interesting finding. Perhaps lipid source can not affect the retention of protein for pigs (Kil et al., 2011).

Increasing the dietary lipid level increased the DE and ME contents of lipids, even though the difference was not significant. The DE and ME contents of SO increased to a greater extent with increasing inclusion level compared with PO. The observation in the DE and ME response is consistent with the observation for the ME content of diets containing SO or tallow (Adeola et al., 2013). That may be due to the changing of the ratio of unsaturated to saturated fatty acids of the dietary lipid in diets with increasing inclusion level. Along with the increased inclusion level of lipid, dietary lipids containing more unsaturated fatty acids can yield more available energy compared with dietary lipids containing more saturated fatty acids (Stahly, 1984; Powles et al., 1995).

The DE and ME of lipids determined with the regression equations were not statistically different from the values determined with the difference method, and were very close to the values at the highest level regardless of lipid sources (unsaturated and saturated). The regression method is largely used to determine the energy content of lipids (Wiseman et al., 1990; Powles et al., 1993; Baidoo et al., 1996; Jørgensen and Fernandez, 2000). However, it is time-consuming and very costly. From the results, we found the coefficient of variance of the determined $\mathrm{DE}$ and $\mathrm{ME}$ values were small when the inclusion level was $10 \%$.
Therefore, the difference method with a $10 \%$ inclusion level can be used to determine the DE and ME contents of lipids for growing pigs.

General theory considers that a greater lipid digestibility is usually in response to a greater DE content for lipid. Previous studies evaluated the DE content of lipids through multiplying the GE by the ATTD of lipid (Wiseman et al., 1990; Powles et al., 1993). However, the contrary results of the current study obtained from difference method showed that the digestibility of the supplemental lipid might be affected by intact fat or other nutrients in the basal diet. Soybean oil is rich in unsaturated fatty acids. However, PO is rich in saturated fatty acids. As the inclusion level of SO increased, the concentration of unsaturated fatty acids in the experimental diets will increase. Likewise for PO, the concentration of saturated fatty acids in the experimental diets will increase. Because unsaturated fatty acids have a greater potential for micelle formation than saturated fatty acids, unsaturated fatty acids are more digestible than saturated fatty acids (Freeman et al., 1968; Stahly, 1984; Powles et al., 1995).

The concentration of apparently digested AEE in the basal diet was about $17 \mathrm{~g} / \mathrm{kg}$ in the current study. The digested AEE mainly was corn oil containing more unsaturated fatty acids $(82.3 \%, \mathrm{NRC}, 2012)$. As the inclusion level of PO increased, the ratio of unsaturated fatty acids to saturated fatty acids in the experimental diets will decrease. This is probably the reason for the ATTD of AEE in PO being lower at a higher lipid level in the current study. Unsaturated fatty acids may aid in the digestion of saturated fatty acids by increasing micelle formation of saturated fatty acids, and the digestibility of saturated fatty acid is improved if unsaturated fatty acids are mixed with saturated fatty acids (Powles et al., 1993).

The values for endogenous loss of AEE for SO and PO were greater than previous values reported for SO (Jørgensen et al., 1993) or corn oil (Kil et al., 2010; Kim et al., 2013). The value for SO was slightly greater than that for PO, but there was no significant difference between them. This might be because SO with a high content of unsaturated fatty acids can facilitate the excretion of endogenous loss in the feces due to the microbial hydrogenation of unsaturated fatty acids in the hindgut (Jørgensen et al., 1993).

The greater ATTD and TTTD of AEE derived from the regression equation in $\mathrm{SO}$ compared with $\mathrm{PO}$ that was observed in the current study is in agreement with previous studies (Powles et al., 1993; Jørgensen et al., 2000). This observation is attributed to the greater digestibility of unsaturated lipid compared with saturated lipid. It was interesting to find that the ATTD of AEE in lipids derived from the regression equation was also very close to the value at the highest level in the present experiment. The 
observation for the AEE in lipids digestibility response is consistent with the observation for the DE and ME response.

\section{CONCLUSION}

The DE content, TTTD, and ATTD of AEE in lipids can be affected by lipid sources. The DE and ME contents in lipids were not affected by inclusion level in the range of $0 \%$ to $10 \%$. Therefore, the difference method can substitute the regression method to determine the $\mathrm{DE}$ and $\mathrm{ME}$ contents of lipids when the inclusion level is $10 \%$.

\section{ACKNOWLEDGMENTS}

This research was financially supported by the Special Public Sector Fund in Agriculture (200903006).

\section{REFERENCES}

Adeola, O. 2001. Digestion and balance techniques in pigs. In: Swine Nutrition, 2nd ed. (Eds. A. J. Lewis and L. L. Southern). CRC Press, New York, USA. pp. 903-916.

Adeola, O., D. C. Mahan, M. J. Azain, S. K. Baidoo, G. L. Cromwell, G. M. Hill, J. E. Pettigrew, C. V. Maxwell, and M. C. Shannon. 2013. Dietary lipid sources and levels for weanling pigs. J. Anim. Sci. 91:4216-4225.

Albin, D. M., M. R. Smiricky, J. E. Wubben, and V. M. Gabert. 2001. The effect of dietary level of soybean oil and palm oil on apparent ileal amino acid digestibility and postprandial flow patterns of chromic oxide and amino acids in pigs. Can. J. Anim. Sci. 81:495-503.

Allee, G. L., D. H. Baker and G. A. Leveille. 1971. Influence of level of dietary fat on adipose tissue lipogenesis and enzymatic activity in the pig. J. Anim. Sci. 33:1248-1254.

AOAC. 2007. Official Methods of Analysis. 18th ed. Association of Official Analytical Chemists, Arlington, VA, USA.

Baidoo, S. K., E. J. Clowes, and F. X. Aherne. 1996. The digestible energy value of canola oil for growing pigs as measured by level of inclusion. Anim. Feed Sci. Technol. 62:111-119.

Bracco, U. 1994. Effect of triglyceride structure on fat absorption. Am. J. Clin. Nutr. 60 (Suppl.):1002S-1009S.

Bruce, K. J., L. K. Karr-Lilienthal, K. E. Zinn, L. L. Pope, D. C. Mahan, N. D. Fastinger, M. Watts, P. L. Utterback, C. M. Parsons, E. O. Castaneda, M. Ellis, and G. C. Fahey. 2006. Evaluation of the inclusion of soybean oil and soybean processing by-products to soybean meal on nutrient composition and digestibility in swine and poultry. J. Anim. Sci. 84:1403-1414.

Dilger, R. N. and O. Adeola. 2006. Estimation of true phosphorus digestibility and endogenous phosphorus loss in growing pigs fed conventional and low-phytate soybean meals. J. Anim. Sci. 84:627-634

Freeman, C. P., D. W. Holme, and E. F. Annison. 1968. The determination of the true digestibilities of interesterified fats in young pigs. Br. J. Nutr. 22:651-660.

Jone, D. B., J. D. Hancock, D. L. Harmon, and C. E. Walker. 1992.
Effects of exogenous emulsifiers and fat sources on nutrient digestibility, serum lipids, and growth performance in weanling pigs. J. Anim. Sci. 70:3473-3482.

Jørgensen, H. and J. A. Fernandez. 2000. Chemical composition and energy value of different fat sources for growing pigs. Acta Agric. Scand. Section A. Anim. Sci. 50:129-136.

Jørgensen, H., V. M. Gabert, M. S. Hedemann, and S. K. Jensen. 2000. Digestion of fat does not differ in growing pigs fed diets containing fish oil, rapeseed oil or coconut oil. J. Nutr. 130:852-857.

Jørgensen, H., S. K. Jensen, and B. O. Eggum. 1996. The influence of rapeseed oil on digestibility, energy metabolism and tissue fatty acid composition in pigs. Acta Agric. Scand. Section A. Anim. Sci. 46:65-75.

Jørgensen, H., K. Jakobsen, and B. O. Eggum. 1993. Determination of endogenous fat and fatty acids at the terminal ileum and on faeces in growing pigs. Acta Agric. Scand. Section A. Anim. Sci. 43:101-106.

Kil, D. Y., F. Ji, L. L. Stewart, R. B. Hinson, A. D. Beaulieu, G. L. Allee, J. F. Patience, J. E. Pettigrew, and H. H. Stein. 2011. Net energy of soybean oil and choice white grease in diets fed to growing and finishing pigs. J. Anim. Sci. 89:448-459.

Kil, D. Y., T. E. Sauber, D. B. Jones, and H. H. Stein. 2010. Effect of the form of dietary fat and the concentration of dietary neutral detergent fiber on ileal and total tract endogenous losses and apparent and true digestibility of fat by growing pigs. J. Anim. Sci. 88:2959-2967.

Kim, B. G., D. Y. Kil, and H. H. Stein. 2013. In growing pigs, the true ileal and total tract digestibility of acid hydrolyzed ether extract in extracted corn oil is greater than in intact sources of corn oil or soybean oil. J. Anim. Sci. 91:755-763.

Kong, C. and O. Adeola. 2014. Evaluation of amino acid and energy utilization in feedstuff for swine and poultry diets. Asian Australas. J. Anim. Sci. 27:917-925.

Li, D. F., R. C. Thale, J. L. Nelssen, D. L. Harmon, G. L. Allee, and T. L. Weeden. 1990. Effect of fat sources and combinations on starter pig performance, nutrient digestibility and intestinal morphology. J. Anim. Sci. 68:3694-3704.

Mendoza, S. M. and E. van Heugten. 2014. Effects of dietary lipid sources on performance and apparent total tract digestibility of lipids and energy when fed to nursery pigs. J. Anim. Sci. 92:627-636.

NRC. 2012. Nutrient Requirements of Swine. 11th rev. ed. Natl. Acad. Press, Washington, DC, USA.

Powles, J., J. Wiseman, D. J. A. Cole, and B. Hardy. 1993. Effect of chemical structure of fats upon their apparent digestible energy value when given to growing/finishing pigs. Anim. Sci. 57:137-146.

Powels, J., J. Wiseman, D. J. A. Cole, and S. Jagger. 1995. Prediction of the apparent digestible energy value of fats given to pigs. Anim. Sci. 61:149-154.

Ramírez, M., L. Amate, and A. Gil. 2001. Absorption and distribution of dietary fatty acids from different sources. Early Hum. Dev. 65 (Suppl. 2):S95-S101.

Rojas-Cano, M. L., V. Ruiz-Guerrero, L. Lara, R. Nieto, and J. F. Aguilera. 2014. Digestibility and energy value of diets containing increasing proportions of olive soapstocks for Iberian crossbred pigs. Anim. Feed Sci. Technol. 191:83-90.

SAS. 1999. SAS User's Guide: Statistics (Version 8.01 ed.). SAS 
Inst. Inc., Cary, NC, USA.

Stahly, T. S. 1984. Use of fats in diets for growing pigs. In: Fats in Animal Nutrition (Ed. J. Wiseman). Butterworths, London, UK. pp. 313-331.

Sukhija, P. S. and D. L. Palmquist. 1988. Rapid method for determination of total fatty acid content and composition of feedstuffs and feces. J. Agric. Food Chem. 36:1202-1206.
Van Soest, P. J., J. B. Robertson, and B. A. Lewis. 1991. Methods for dietary fiber, neutral detergent fiber, and nonstarch polysaccharides in relation to animal nutrition. J. Dairy Sci. 74:3583-3597.

Wiseman, J., D. J. A. Cole, and B. Hardy. 1990. The dietary energy values of soya-bean oil, tallow and their blends for growing/finishing pigs. Anim. Prod. 50:513-518. 